\title{
Use of Fluorescent Dyes in Endoscopy and Diagnostic Investigation
}

\author{
Arthur Hoffman $^{a}$ Raja Atreya ${ }^{b}$ Timo Rath $^{b}$ Markus F. Neurath ${ }^{b}$ \\ ${ }^{a}$ Department of Internal Medicine III, Clinic Aschaffenburg-Alzenau, Aschaffenburg, Germany; ${ }^{b}$ First Department of \\ Medicine, Friedrich Alexander University Erlangen-Nuernberg, Erlangen, Germany
}

\section{Keywords}

Optical contrast techniques - Real-time optical diagnosis . Fluorescent tracers - Visualization of specific biochemical processes

\begin{abstract}
Background: The advancement of innovative endoscopic technology in terms of improving the visualization of the mucosa has been of significant benefit. Summary: Advancements in image resolution, software processing, and optical filter technology have resulted in several techniques complemental to traditional white light endoscopy. These new techniques provide a real-time optical diagnosis as well as virtual histology of detected lesions. Optical molecular imaging permits a functional assessment within cells. Key Message: Optical molecular imaging provides an understanding of cellular processes and permits validation of the specificity of fluorescent tracers and the possibility of quantifying the signal.

(c) 2020 S. Karger AG, Basel
\end{abstract}

\section{Introduction}

White light endoscopy (WLE) has been the gold standard for the detection of lesions in the gastrointestinal tract. The rapid advancement of innovative endoscopic technology in terms of improving the visualization of the mucosa has been of significant benefit.
Advancements in image resolution, software processing, and optical filter technology have resulted in the commercial availability of high-definition endoscopy as well as optical contrast techniques such as narrow-band imaging, flexible spectral imaging color enhancement, and i-scan.

Along with autofluorescence imaging and confocal laser endomicroscopy, these techniques complement traditional WLE. They have the potential to serve as red flag techniques in terms of improving the detection of mucosal abnormalities. The techniques provide a real-time optical diagnosis as well as virtual histology of detected lesions.

Optical molecular imaging (OMI) permits organelle staining in live cells as well as their functional assessment to confirm the identity of specific proteins or targets within cells. It also provides a better understanding of cellular processes and permits validation of the specificity of fluorescent tracers, including the possibility of quantifying the signal.

\section{Multimodal Endoscopy}

During WLE, broadband white light in the visible spectral region illuminates the tissue, and images are acquired in the reflectance mode. WLE detects lesions based on structural changes or discoloration of the epithelial surface and may be used to guide the acquisition of tissue biopsies [1, 2] (Fig. 1). 


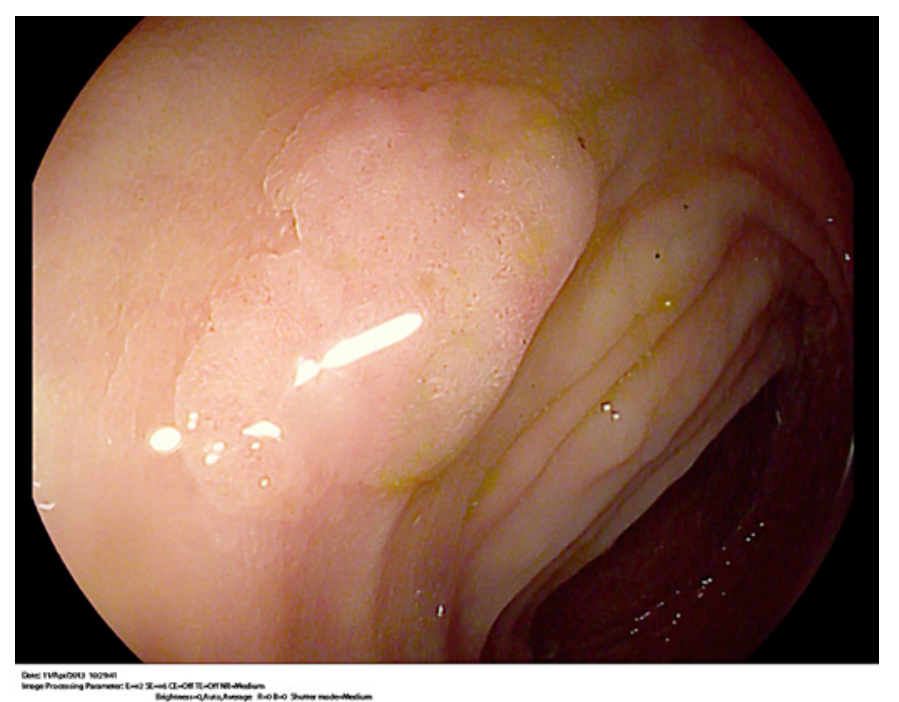

Fig. 1. White light of a flat colonic lesion.

Despite the efficacy of current endoscopy, small and inconspicuous lesions or serrated adenomas tend to be flat and do not exhibit detectable discoloration relative to normal tissue in the three reflectance color channels (red/ green/blue, RGB) used in WLE [1]. This makes the detection of disease and the acquisition of targeted biopsies with conventional WLE a challenging issue [1].

Missed lesions are a main risk factor for advanced or interval cancers, particularly in high-risk patients such as those with the Lynch syndrome. Consequently, there is strong clinical interest in the development of new endoscopic screening methods that may enhance contrast for precancerous or inflammatory lesions, permitting more targeted biopsies and improving diagnostic performance [1-8].

Many clinical endoscopes acquire spectral data. However, the added value of methods such as narrow-band imaging (two illumination bands and RGB detection), autofluorescence imaging (two illumination bands and monochrome detection), or trimodal imaging (combination of narrow-band imaging and autofluorescence imaging with high-definition WLE) have been extensively investigated, but were not associated with any significant improvement in adenoma detection rates [4, 9-11].

On the other hand, modern multimodal endoscopy can potentially improve the diagnostic performance of endoscopy by simultaneously addressing numerous contrast mechanisms [12]. The application of a targeted fluorescent contrast agent, consisting of a fluorescent dye conjugated to a targeting moiety, designed to highlight a biological process that is dysregulated in the diseased area, is referred to as "optical molecular imaging" (OMI). OMI was found to be promising in terms of better endoscopic inspection of the gastrointestinal tract $[1,3,13]$. In clinical endoscopic studies, OMI has served as a "red flag technique," prompting targeted tissue biopsy in studies of colorectal and esophageal disease $[4,14]$ (Fig. 2).

Molecular imaging allows dynamic as well as quantitative visualization of specific biochemical processes. It has been useful for early-stage diagnosis. Furthermore, its curative effect in monitoring disease, drug development, gene therapy, and other fields has also been proven. Its limitations stem from a paucity of multifunctional molecular imaging agents, the limitations of imaging technology (such as poor sensitivity to complement contrast agents), and the lack of nonradiative molecular imaging that can provide both structural and functional information.

\section{Principles of Fluorescence Imaging}

Fluorescence diagnostic imaging is a relatively new technique that involves the use of a photosensitizing drug to visualize lesions through tissue fluorescence.

Fluorescence molecular endoscopy (FME) or fluorescence imaging is based on the molecular absorption of light: a region of interest containing the fluorophore is excited at a specific wavelength, and light at a different wavelength is emitted. Each fluorophore has a characteristic excitation spectrum that is identified by monitoring the fluorescence emission while the fluorophore is excited by a range of consecutive wavelengths $[15,16]$.

Fluorescence imaging is known for its high detection sensitivity, specificity, and spatial resolution [17].

When electrons go from an excited state to the ground state, there is loss of vibrational energy. The emission spectrum is shifted to longer wavelengths than the excitation spectrum (a phenomenon known as "Stoke's shift") $[18,19]$. The emission intensity peak is lower than the excitation peak. In order to achieve maximum fluorescence intensity, the fluorophore is usually excited at the peak wavelength of the excitation curve, and the emission detection is typically the peak wavelength of the emission curve. The fluorescence method is regenerative and permits longitudinal imaging, unlike the radionuclide decay process in nuclear imaging [20].

Fluorescence imaging can use intrinsic tissue properties such as contrast (autofluorescence) and also image exogenous contrast agents. The three primary processes that typically govern the interaction of photons with tissues are light absorption, light scattering, and fluorescence emission. In short, light absorption and scattering decrease with increasing wavelength. Below $700 \mathrm{~nm}$, tissue absorption results in a low penetration depth of light (a few millimeters), allowing no more than a superficial assessment of tissues in the visible wavelength. The light absorption is caused by oxy- and deoxyhemoglobin, melanin at wavelengths $<700 \mathrm{~nm}$, lipid, and water at wavelengths $>1,000 \mathrm{~nm}[18,19]$. 

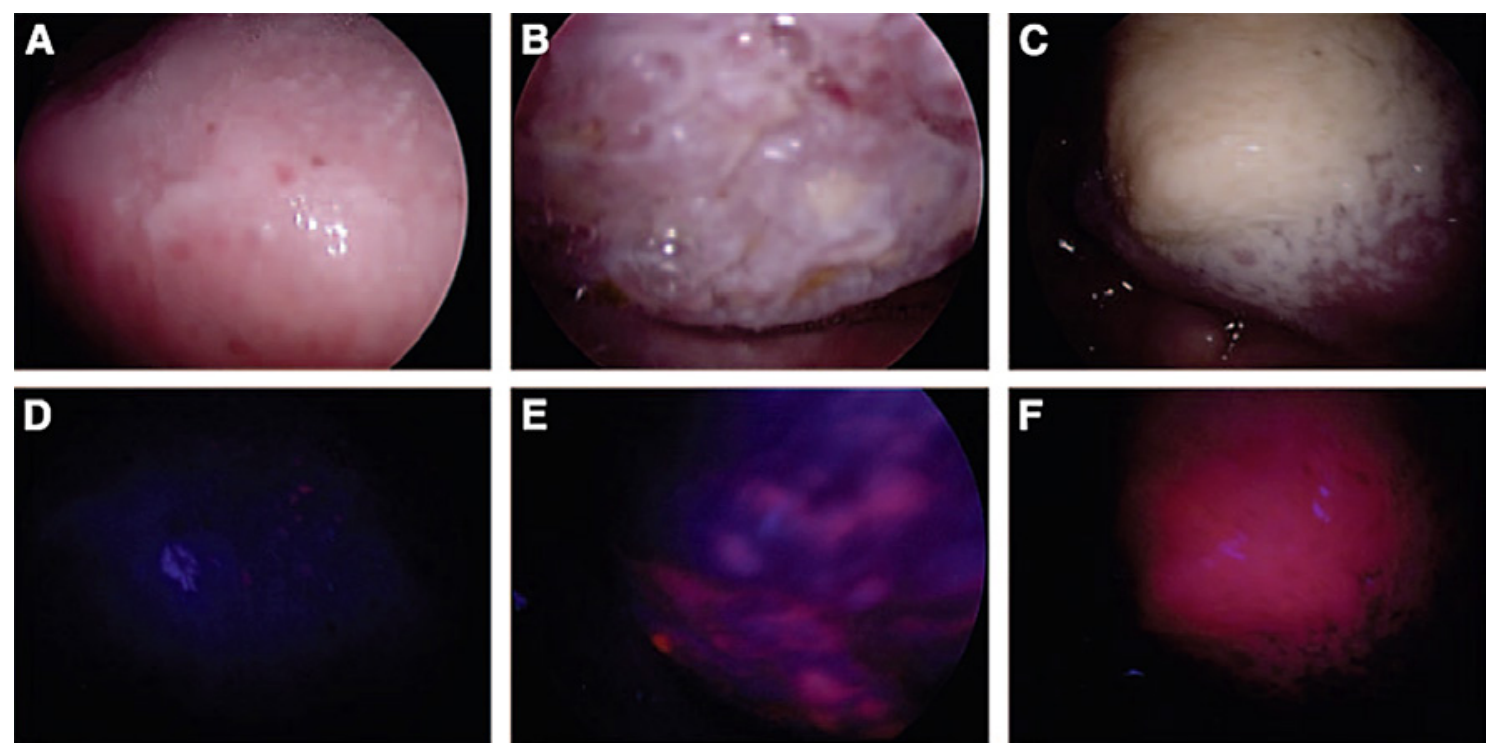

Fig. 2. White light (A-C) and hypericin fluorescence (D-F) endoscopic images of normal (A, D), hyperplastic (B, $\mathbf{E})$, and SCC $(\mathbf{C}, \mathbf{F})$ tongues. The fluorescence images show a progressive increase in the red-to-blue $(\mathrm{R} / \mathrm{B})$ intensity ratios from normal (R/B ratio 0.3 ) to hyperplastic (R/B ratio 1.0) to SCC (R/B ratio 2.0) tissue. Copyright: Thong et al. [76].

Since the absorption coefficient of tissue is significantly lower in the near-infrared (NIR) region (700-900 nm) than in the visible region, NIR light can penetrate to a depth of several centimeters into tissue [21,22]. A major goal of optical imaging has been the development of suitable targeted NIR fluorochromes with high molar extinction coefficients, good quantum yields, and specific tissue binding $[21,22]$.

\section{OMI and Contrast Agents}

The effective implementation of molecular imaging and treatment approaches requires the identification of target proteins that can detect aberrant cells with high sensitivity. DNA changes that occur in premalignant and malignant lesions must be addressed in order to identify relevant target proteins. The difference between these lesions and their healthy surrounding cells is that the former exhibit genomic alterations that might lead to downstream changes in gene expression levels. These changed gene expression levels influence the downstream cellular phenotype, and thus affect protein expression levels [23, 24].

Nevertheless, these genomically driven changes in gene expression levels are subtle and usually overshadowed by nongenetic processes, such as the circadian rhythm or postprandial metabolic influences [25].

Due to the minimal NIR fluorescence contrast generated by most tissues, in vivo studies require exogenous contrast agents. Such targeted molecular agents consist of a signal component and a targeting component. The con- trast agents must also have adequate contact time with the target for the binding to occur, and be retained by the target while nonbound material is cleared. Unconjugated organic NIR fluorophores are typically less than $1.2 \mathrm{kDa}$, but have widely different bio-distributions and pharmacokinetics, depending on their charge and the properties of their conjugated targeted molecule. As the charge per molecule is increased, fluorophores remain extracellular and their plasma half-life increases proportionally [26]. Clearance is typically accomplished by a combination of renal filtration and excretion into bile.

Many OMI contrast agents are currently under preclinical and clinical investigation, and novel products of better quality are being developed $[1,4,27,28]$. For efficient dye-based fluorescent tracing in vivo, the dye must efficiently and homogenously stain the cells without affecting their viability or function, while also transferring to daughter cells. Additionally, the stain should not be transferred to adjacent resident cells, as this would render it useless for tracing purposes.

One important class of organic fluorophores is indocyanine. Indocyanine green (ICG), one of the most common of these, was approved by the FDA for human use in 1958. It is one of the least toxic agents administered to humans, with the only adverse reaction being rare anaphylaxis. Furthermore, ICG is tetra-sulfonated; this increases its solubility and aqueous quantum yield [29]. The excitation peak of this class lies between 760 and $800 \mathrm{~nm}$, and its emission peak between 790 and $830 \mathrm{~nm}[30,31]$.

Another important consideration for in vivo molecular probes is toxicity. Without charged groups, indocya- 
nines can be quite toxic because of their intracellular accumulation [32]. However, disulfonated ICG has been used in humans for over 50 years and has an excellent safety profile. ICG has been employed for a variety of applications, including angiograms of the eye and brain, the determination of postresection tumor margins, and the identification of gastrointestinal tract lesions, to name a few [30, 33-35].

Although ICG provides a contrast mechanism, its enhanced permeability and retention create limitations. For this reason, and for the identification of specific pathological tissues, interest in the development of tumor-specific optical contrast agents has been growing rapidly $[1$, $4,27,28]$.

Today we have a plethora of targeting components, such as a small molecule, peptide, antibody, or aptamer, which are applied to ligand-directed imaging agents.

\section{Overview of Ligand-Directed Imaging Agents}

The success of a fluorescent tracer as a useful imaging tool is dependent on several characteristics; these include the different types of synthetic fluorophores and their administered quantities, as well as the targeting moiety and the type of "carrier molecule" [36]. Several types of molecules can be deployed as dye carriers. Monoclonal antibodies, but also peptides, lectins, antibody fragments, or nanoparticles can be used to form the "backbone" of the tracer. All of these carrier molecules have their specific pros and cons; monoclonal antibodies are highly specific and permit specific targeting, but their high molecular weight (approximately $150 \mathrm{kDa}$ ) leads to slow delivery, while their long half-life and slow wash-out cause a high background signal [37].

Peptide tracers possess favorable properties for in vivo use, as these are low-molecular-weight molecules providing high clonal diversity. Moreover, their immunogenicity - and their costs - are low. However, since small peptide tracers "wash out" relatively quickly, high doses of the tracer need to be administered in order to achieve adequate accumulation. Other disadvantages include their variable affinity, the consequent risk of their lack of efficacy, and uncertainty of appropriate targeting $[37,38]$. As binding sites and targeting moieties can be affected by conjugation with dye molecules, monoclonal antibodies or lectins of a relatively large size (20-200 kDa) are less prone to these risks. This results in more dye attachment and a higher fluorescence intensity per unit. Last but certainly not least, fluorescent tracers differ in terms of their fluorescent "status." A distinction can be made between "always-on-probes" and so-called "smart activatable probes." The first type of tracer irradiates fluorescence nonselectively when excited by light from a specific wave- length. In other words, its specificity and utility are biodistribution dependent, and its affinity for binding to the target site compared to the accumulation of unbound or nonspecifically bound agent determines the tumor-tobackground signal and its distinctiveness [37-39]. In contrast, "smart activatable probes" are unique because these agents first need to be activated by specific biomarkers located at the target site in order to become excited. In their original state their fluorescent activity is repressed by quenching of the dye molecules, rendering the fluorophore undetectable. After dequenching, for example due to cleavage by proteases, these probes show a significant increase in fluorescent activity [38-41]. This "activatable" feature creates improved target-to-background ratios, which is highly relevant for small lesions and for early detection of lesions. Therefore, this "activatable" feature makes these tracers interesting for future clinical application and further research, particularly in the field of endoscopic imaging. Furthermore, targeted fluorescent contrast agents are advantageous because they combine reflectance-based imaging in the visible wavelength range with exogenous targeted fluorescent contrast agents in the NIR wavelength, showing a relatively high signal-tobackground ratio [1, 13, 42-44].

Fluorescent dyes excited by light in the NIR spectrum (665-900 nm), also known as the so-called "NIR window," are considered optimal because they create minimum tissue autofluorescence and provide maximum tissue penetration.

Previous studies have employed fluorophores excited by light from the visible spectrum $(350-550 \mathrm{~nm}$; such as FITC), which produce a high autofluorescent signal and hence high background signals or "visual noise" [4, 27, 45]. The low autofluorescence of human tissue in the NIR light spectrum improves target-to-background ratios. Secondly, NIR wavelengths penetrate deeper into the target tissue because they are less prone to interference due to tissue absorption (such as hemoglobin) and tissue scattering [46]. Finally, NIR fluorescence enables the investigator to concurrently capture visible white light and thus superimpose fluorescent signals on morphologic images in real time.

\section{Multi- or Hyperspectral Imaging}

Molecular optical imaging may be defined as visualizing the molecular signature of cells in vivo and the biological response (such as upregulation of a particular cell surface receptor) that may precede visible structural changes. However, the limited spectral range of these methods provides no more than a qualitative picture of the epithelium. Methods with finer sampling of the spectral response, such as multi- or hyperspectral imaging (MSI/HSI) systems ( $\approx 10$ and 100 spectral color channels, 
Fig. 3. Images acquired during ex vivo molecular fluorescence colonoscopy of IgG$800 \mathrm{CW}$ (I) and bevacizumab-800CW (II) targeted tumors (3.3 $\mathrm{mm}$ in size). Endoscopy images were obtained with video endoscope and fiber bundle. White-light, fluorescence, and composite images of fiber bundle were real-time-projected. Copyright: Tjalma et al. [28].

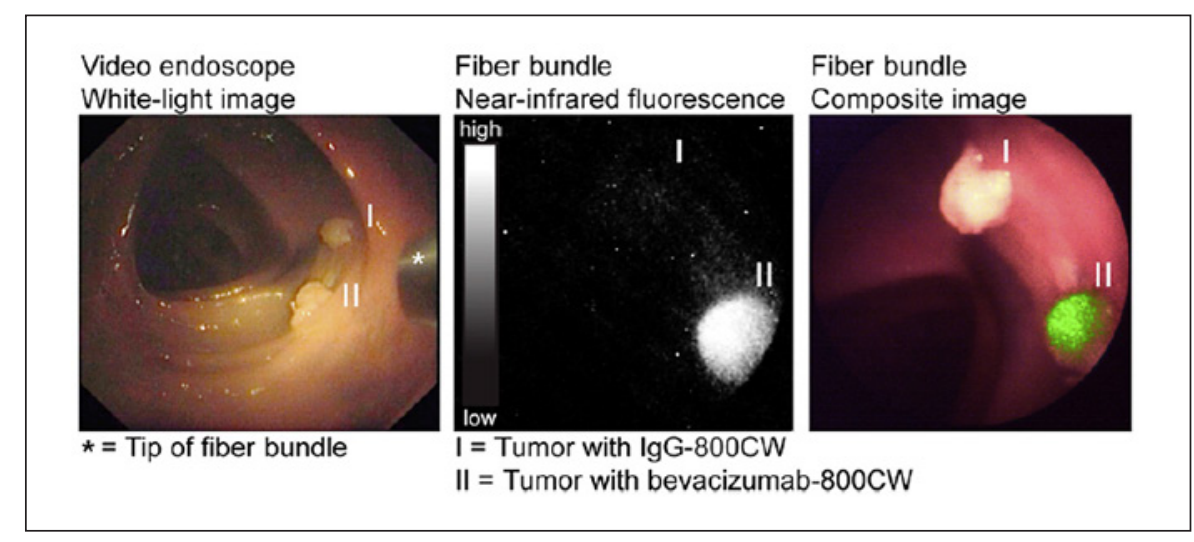

respectively) may permit quantitative assessment of functional tissue properties and more detailed statistical classification of the spectral changes that occur during disease $[43,44]$. The use of reflectance-based MSI/HSI systems in biomedical applications has, for example, been shown to increase contrast in vascular investigations, wound healing, ophthalmology, cancer diagnosis, and for the determination of tumor resection margins [47-57].

These potential molecular targets and the promising approach of using molecular targeted tracers for advanced, noninvasive therapeutic purposes in the near future constitute a truly theranostic approach.

\section{Molecular Targets}

Cells contain subcellular structures and signaling substances responsible for carrying out essential functions for cell survival. Due to their specialized functions and welldefined nature, these structures should ideally be labeled in cell biology studies. More specifically, the use of specific dyes permits selective staining of specific organelles and signal substances without increasing cytotoxicity. Specific staining in live cells can help scientists to confirm the identity of specific proteins or targets within cells and thus achieve a better understanding of cellular processes.

Based on the established role of vascular endothelial growth factor A (VEGF-A) in tumor angiogenesis, it is an early target protein for molecular imaging of premalignant and malignant gastrointestinal lesions [58]. Since solid tumors cannot grow beyond $2-3 \mathrm{~mm}^{3}$ without adequate blood supply, most human cancer types express high levels of VEGF-A [58-63]. Therefore, elevated VEGF-A levels are present in early dysplastic and malignant gastrointestinal lesions. VEGF-A levels increase throughout the dysplasia-carcinoma sequence, also known as the so-called early angiogenic switch $[64,65]$. VEGF-A is markedly overexpressed specifically in colorectal lesions that are easily missed during endoscopy, such as SSA/P lesions and Lynch adenomas.
The ability to visualize colonic lesions in the simulation model, in combination with the good manufacturing practice-based production of $800 \mathrm{CW}$-labeled antibodies, should facilitate rapid adoption of this technique in the clinical setting (Fig. 3).

Quantitative fluorescence endoscopy (QFE) is a new technique that can visualize and quantify fluorescently tagged tumor tissue [66]. In one study, patients with locally advanced rectal cancer received neoadjuvant chemoradiotherapy and then underwent surgery for local disease control (Fig. 4).

The identification of patients with complete clinical response before surgery is a subject of increasing interest because the nonsurgical management of these patients is associated with high survival rates, reduced morbidity, and improved functional outcomes [67-71]. However, assessing tumor response after neoadjuvant chemoradiotherapy is challenging. QFE can target VEGF-A to detect a residual tumor in the rectum after neoadjuvant chemoradiotherapy. Thus, VEGFA-targeted QFE can be of additional value in restaging patients with locally advanced rectal cancer.

QFE detects significantly higher fluorescence in tumor compared with normal rectal tissue and fibrosis, and improves the predictive power of the final pathology results in $16 \%$ of patients compared with standard MRI and WLE [72].

Interestingly, $15-27 \%$ of patients had a complete response on pathological investigation $[2,3]$. In untreated patients, QFE clearly showed enhanced fluorescence in all rectal tumors compared with normal rectal tissue.

In conclusion, the results of preliminary pilot studies, even in a small group of patients, are encouraging and constitute a first step towards QFE for tumor response evaluation after neoadjuvant treatment [66].

Fluorescent imaging can be also used in for making decisions with regard to treatment response. Tumor necrosis factor (TNF) is a cell signaling protein (cytokine) in systemic inflammation, known to be involved in regulating immune cells and generally overexpressed in inflammatory bowel disease [73]. For this reason, TNF in- 


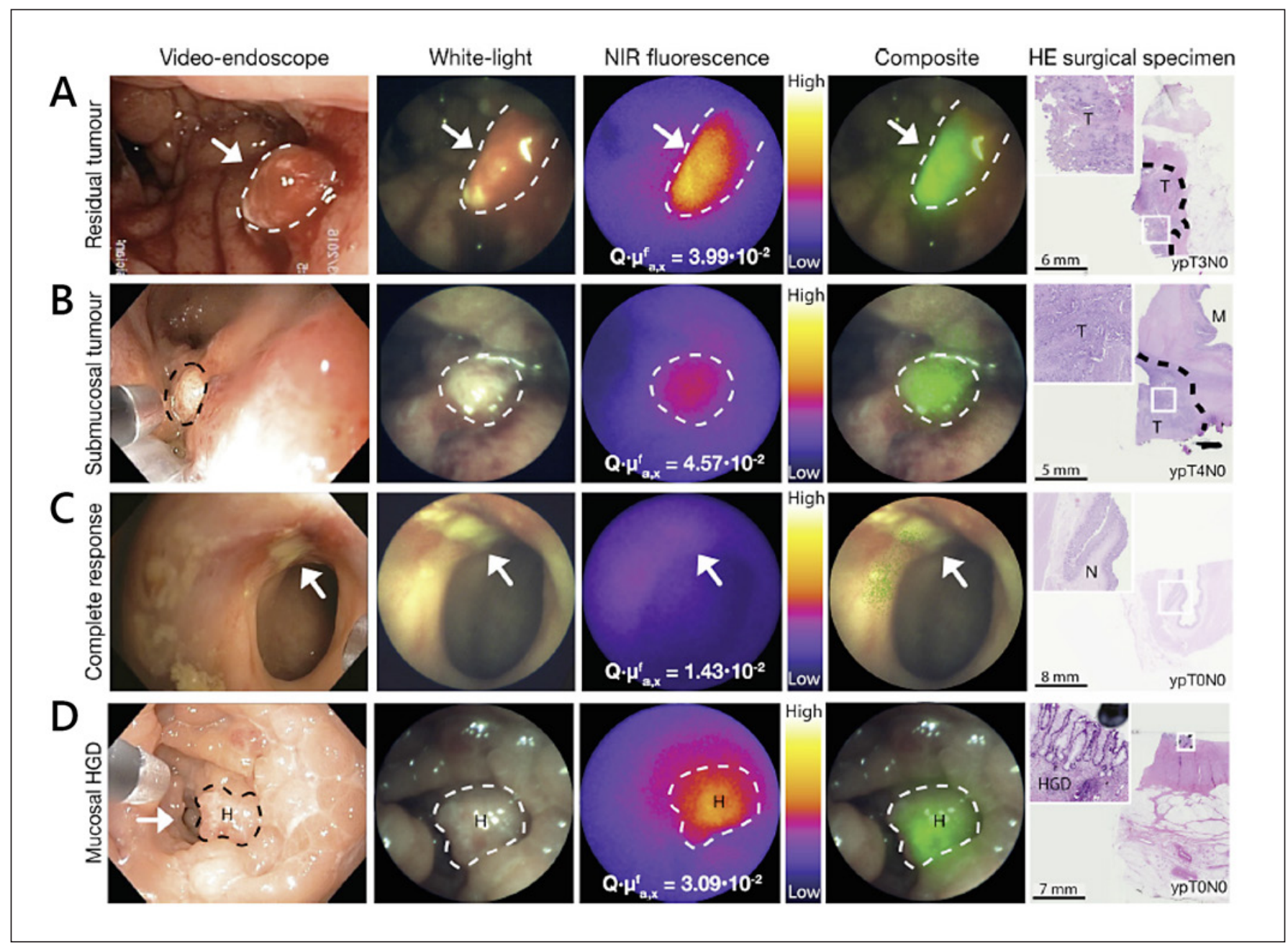

Fig. 4. Representative images of the quantitative fluorescence endoscopy (QFE) procedure after neoadjuvant chemoradiotherapy of a patient with residual tumor (A), submucosal tumor (B), mucosal high-grade dysplasia (HGD) (C) and a pathological complete response (D). From left to right: a high-definition white-light video endoscope image of the rectal tumor; a white-light image from the QFE fiberoptic, followed by the corresponding near-infrared (NIR) fluorescence image captured with an exposure time of $100 \mathrm{~ms}$ and the composite image of both modalities. The maximum quantified fluorescence value is depicted on the NIR fluorescence image. The rightmost column depicts an HE staining of the surgical specimen in which the pathological TNM stage is indicated. Copyright: Tjalma et al. [66].

hibitors are commonly used therapeutic agents. However, some patients do not respond to these.

A fluorescent antibody directed against TNF has already been tested in a clinical trial in Crohn's disease patients to predict response to subsequent anti-TNF therapy. It could be shown that this diagnostic approach of performing TNF-targeted NIR-FME at baseline was able to predict clinical and endoscopic response to therapy based on the amount of mucosal TNF expression. Thus, patients who are likely to benefit from anti-TNF treatment regimens can be selected accordingly [74, 75]. Similar molecular endoscopy approaches have already been successfully tested ex vivo to predict therapeutic response to therapy with the anti $\alpha_{4} \beta_{7}$ integrin antibody vedolizumab in Crohn's disease patients [73].

\section{Conclusion}

One of the prime objectives of the study was to facilitate the use of FME in the clinical setting and illustrate the potential of FME as a means of improving the detection of gastrointestinal lesions. A further aim was to visualize the molecular signature of cells in vivo and their biological response.

FME is certainly a milestone in this field, but technical improvements will be needed before the procedure can be integrated into clinical routine. Further research in larger study populations will be required in order to verify the advantages of FME in terms of detection rates and surveillance strategies. Furthermore, current research has yielded promising molecular targets for future use. These 
novel targets can help to improve imaging sensitivity and specificity. Last but not least, the theranostic application of molecular-targeted antibodies will permit selective cancer treatment.

The results of preliminary pilot studies are encouraging and potentially a first step towards QFE for the evaluation of disease response after treatment.

\section{Disclosure Statement}

A. Hoffman has no conflicts of interest to declare. M.F. Neurath has acted as a consultant for pharmaceutical, device, or biotechnology companies: Bionorica SE, e.Bavarian Health GmbH, Boehringer Ingelheim $\mathrm{GmbH}$ and Co. KG, F. Hoffmann La Roche GmbH, Genentech Inc., Hexal AG, Index Pharmaceuticals AB, Janssen-Cilag GmbH, MSD Sharp and Dohme GmbH, Pentax Eu- rope GmbH, PPM Services S.A., and Takeda Pharma Vertrieb $\mathrm{GmbH}$ and Co. KG. He also received payment for lectures including service on speakers' bureaus: AbbVie Deutschland $\mathrm{GmbH}$ and Co. KG, Falk Foundation, Janssen-Cilag GmbH, and Pentax Europe GmbH. R. Atreya and T. Rath have no conflicts of interest to declare.

\section{Funding Sources}

No funding was provided for this study.

\section{Author Contributions}

A. Hoffman wrote the manuscript and was responsible for the literature research. R. Atreya, T. Rath, and M.F. Neurath gave advice, particularly in the molecular imaging section.

\section{References}

1 Lee JH, Wang TD. Molecular endoscopy for targeted imaging in the digestive tract. Lancet Gastroenterol Hepatol. 2016 Oct;1(2):147-55.

2 Krishnamoorthi R, Iyer PG. Molecular biomarkers added to image-enhanced endoscopic imaging: will they further improve diagnostic accuracy? Best Pract Res Clin Gastroenterol. 2015 Aug;29(4):561-73.

3 Sturm MB, Wang TD. Emerging optical methods for surveillance of Barrett's oesophagus. Gut. 2015 Nov;64(11):1816-23.

4 Joshi BP, Duan X, Kwon RS, Piraka C, Elmunzer BJ, Lu S, et al. Multimodal endoscope can quantify wide-field fluorescence detection of Barrett's neoplasia. Endoscopy. 2016 Feb; 48(2):A1-13.

5 Lee CM, Engelbrecht CJ, Soper TD, Helmchen F, Seibel EJ. Scanning fiber endoscopy with highly flexible, $1 \mathrm{~mm}$ catheterscopes for widefield, full-color imaging. J Biophotonics. 2010 Jun;3(5-6):385-407.

6 Qiu L, Pleskow DK, Chuttani R, Vitkin E, Leyden J, Ozden N, et al. Multispectral scanning during endoscopy guides biopsy of dysplasia in Barrett's esophagus. Nat Med. 2010 May;16(5): 603-6.

7 di Pietro M, Boerwinkel DF, Shariff MK, Liu X, Telakis E, Lao-Sirieix P, et al. The combination of autofluorescence endoscopy and molecular biomarkers is a novel diagnostic tool for dysplasia in Barrett's oesophagus. Gut. 2015 Jan;64(1): 49-56.

8 Garcia-Allende PB, Glatz J, Koch M, Tjalma JJ, Hartmans E, Terwisscha van Scheltinga AG, et al. Towards clinically translatable NIR fluorescence molecular guidance for colonoscopy. Biomed Opt Express. 2013 Dec;5(1):78-92.

9 East JE, Suzuki N, Stavrinidis M, Guenther T, Thomas HJ, Saunders BP. Narrow band imaging for colonoscopic surveillance in hereditary non-polyposis colorectal cancer. Gut. 2008 Jan; 57(1):65-70.

10 Ramsoekh D, Haringsma J, Poley JW, van Putten $\mathrm{P}$, van Dekken H, Steyerberg EW, et al. A back-to-back comparison of white light video endoscopy with autofluorescence endoscopy for adenoma detection in high-risk subjects. Gut. 2010 Jun;59(6):785-93.

11 Chung SJ, Kim D, Song JH, Kang HY, Chung GE, Choi J, et al. Comparison of detection and miss rates of narrow band imaging, flexible spectral imaging chromoendoscopy and white light at screening colonoscopy: a randomised controlled back-to-back study. Gut. 2014 May; 63(5):785-91.

12 Waterhouse DJ, Fitzpatrick CR, di Pietro M, Bohndiek SE. Emerging optical methods for endoscopic surveillance of Barrett's oesophagus. Lancet Gastroenterol Hepatol. 2018 May; 3(5):349-62.

13 Garcia-Allende PB, Glatz J, Koch M, Tjalma JJ, Hartmans E, Terwisscha van Scheltinga AG, et al. Towards clinically translatable NIR fluorescence molecular guidance for colonoscopy. Biomed Opt Express. 2013 Dec;5(1):78-92.

14 Burggraaf J, Kamerling IM, Gordon PB, Schrier L, de Kam ML, Kales AJ, et al. Detection of colorectal polyps in humans using an intravenously administered fluorescent peptide targeted against c-Met. Nat Med. 2015 Aug;21(8): 955-61.

15 O'Leary MA, Boas DA, Li XD, Chance B, Yodh AG. Fluorescence lifetime imaging in turbid media. Opt Lett. 1996 Jan;21(2):158-60.

16 Ntziachristos V, Weissleder R. Experimental three-dimensional fluorescence reconstruction of diffuse media by use of a normalized Born approximation. Opt Lett. 2001 Jun;26(12):893-5.

17 Rao J, Dragulescu-Andrasi A, Yao H. Fluorescence imaging in vivo: recent advances. Curr Opin Biotechnol. 2007 Feb;18(1):17-25.

18 Tromberg BJ, Shah N, Lanning R, Cerussi A, Espinoza J, Pham T, et al. Non-invasive in vivo characterization of breast tumors using photon migration spectroscopy. Neoplasia. 2000 JanApr;2(1-2):26-40.

19 Frangioni JV. In vivo near-infrared fluorescence imaging. Curr Opin Chem Biol. 2003 Oct;7(5):626-34.

20 Achilefu S. Lighting up tumors with receptorspecific optical molecular probes. Technol Cancer Res Treat. 2004 Aug;3(4):393-409.
21 Grosenick D, Wabnitz H, Rinneberg HH, Moesta KT, Schlag PM. Development of a time-domain optical mammograph and first in vivo applications. Appl Opt. 1999 May;38(13):2927-43.

22 Shah, K. \& Weissleder, R. Molecular optical imaging: applications leading to the development of present day therapeutics. NeuroRx. 2005 Apr;2(2):215-225.

23 Fehrmann RS, Karjalainen JM, Krajewska M, Westra HJ, Maloney D, Simeonov A, et al. Gene expression analysis identifies global gene dosage sensitivity in cancer. Nat Genet. 2015 Feb; 47(2):115-25.

24 Vogelstein B, Fearon ER, Hamilton SR, Kern SE, Preisinger AC, Leppert M, et al. Genetic alterations during colorectal-tumor development. N Engl J Med. 1988 Sep;319(9):525-32.

25 Kerbel RS. Tumor angiogenesis: past, present and the near future. Carcinogenesis. $2000 \mathrm{Mar}$; 21(3):505-15.

26 Hamaoka T, Katsumura T, Murase N, Nishio S, Osada T, Sako T, et al. Quantification of ischemic muscle deoxygenation by near infrared time-resolved spectroscopy. J Biomed Opt. 2000 Jan;5(1):102-5.

27 Bird-Lieberman EL, Neves AA, Lao-Sirieix P, O’Donovan M, Novelli M, Lovat LB, et al. Molecular imaging using fluorescent lectins permits rapid endoscopic identification of dysplasia in Barrett's esophagus. Nat Med. 2012 Jan; 18(2):315-21.

28 Tjalma JJ, Garcia-Allende PB, Hartmans E, Terwisscha van Scheltinga AG, Boersma-van Ek W, Glatz J, et al. Molecular fluorescence endoscopy targeting vascular endothelial growth factor a for improved colorectal polyp detection. J Nucl Med. 2016 Mar;57(3):480-5.

29 Herbort CP, LeHoang P, Guex-Crosier Y. Schematic interpretation of indocyanine green angiography in posterior uveitis using a standard angiographic protocol. Ophthalmology. 1998 Mar; 105(3):432-40.

30 Chen SJ, Lee AF, Lee FL, Liu JH. Indocyanine green angiography of central serous chorioretinopathy. Zhonghua Yi Xue Za Zhi (Taipei). 1999 Sep;62(9):605-13. 
31 Sima PD, Kanofsky JR. Cyanine dyes as protectors of K562 cells from photosensitized cell damage. Photochem Photobiol. 2000 Apr; 71(4):413-21.

32 Nakayama A, Bianco AC, Zhang CY, Lowell BB, Frangioni JV. Quantitation of brown adipose tissue perfusion in transgenic mice using near-infrared fluorescence imaging. Mol Imaging. 2003 Jan;2(1):37-49.

33 Herbort CP, LeHoang P, Guex-Crosier Y Schematic interpretation of indocyanine green angiography in posterior uveitis using a standard angiographic protocol. Ophthalmology. 1998 Mar; 105(3):432-40.

34 Haglund MM, Hochman DW, Spence AM, Berger MS. Enhanced optical imaging of rat gliomas and tumor margins. Neurosurgery. 1994 Nov;35(5):930-40; discussion 940-1.

35 Haglund MM, Berger MS, Hochman DW. Enhanced optical imaging of human gliomas and tumor margins. Neurosurgery. 1996 Feb;38(2) 308-17.

36 Kobayashi H, Ogawa M, Alford R, Choyke PL, Urano Y. New strategies for fluorescent probe design in medical diagnostic imaging. Chem Rev. 2010 May;110(5):2620-40.

37 Chen K, Chen X. Design and development of molecular imaging probes. Curr Top Med Chem. 2010;10(12):1227-36.

38 Goetz M, Wang TD. Molecular imaging in gastrointestinal endoscopy. Gastroenterology. 2010 Mar;138(3):828-33.e1.

39 Weissleder R, Tung CH, Mahmood U, Bogdanov A Jr. In vivo imaging of tumors with protease-activated near-infrared fluorescent probes. Nat Biotechnol. 1999 Apr;17(4):375-8.

40 Marten K, Bremer C, Khazaie K, Sameni M, Sloane B, Tung CH, et al. Detection of dysplastic intestinal adenomas using enzyme-sensing molecular beacons in mice. Gastroenterology. 2002 Feb;122(2):406-14.

41 Funovics M, Weissleder R, Tung CH. Protease sensors for bioimaging. Anal Bioanal Chem. 2003 Nov;377(6):956-63.

42 Sturm MB, Wang TD. Emerging optical methods for surveillance of Barrett's oesophagus. Gut. 2015 Nov;64(11):1816-23.

43 Lu G, Halig L, Wang D, Qin X, Chen ZG, Fei B. Spectral-spatial classification for noninvasive cancer detection using hyperspectral imaging. J Biomed Opt. 2014;19(10):106004

44 Gao L, Smith RT. Optical hyperspectral imaging in microscopy and spectroscopy - a review of data acquisition. J Biophotonics. 2015 Jun; 8(6):441-56.

45 Sturm MB, Joshi BP, Lu S, Piraka C, Khondee $\mathrm{S}$, Elmunzer BJ, et al. Targeted imaging of esophageal neoplasia with a fluorescently labeled peptide: first-in-human results. Sci Transl Med. 2013 May;5(184):184ra61.

46 Hilderbrand SA, Weissleder R. Near-infrared fluorescence: application to in vivo molecular imaging. Curr Opin Chem Biol. 2010 Feb; 14(1):71-9.

47 Lu G, Fei B. Medical hyperspectral imaging: a review. J Biomed Opt. 2014 Jan;19(1):10901.

48 Johnson WR, Wilson DW, Fink W, Humayun M, Bearman G. Snapshot hyperspectral imaging in ophthalmology. J Biomed Opt. 2007 JanFeb;12(1):014036
49 Calin MA, Coman T, Parasca SV, Bercaru N, Savastru R, Manea D. Hyperspectral imagingbased wound analysis using mixture-tuned matched filtering classification method. J Biomed Opt. 2015 Apr;20(4):046004.

50 Ren W, Gan Q, Wu Q, Zhang S, Xu R. Quasisimultaneous multimodal imaging of cutaneous tissue oxygenation and perfusion. J Biomed Opt. 2015 Dec;20(12):121307

51 Li H, Liu W, Dong B, Kaluzny JV, Fawzi AA, Zhang HF. Snapshot hyperspectral retinal imaging using compact spectral resolving detector array. J Biophotonics. 2017 Jun; 10(6-7):830-9.

52 MacKenzie LE, Choudhary TR, McNaught AI, Harvey AR. In vivo oximetry of human bulbar conjunctival and episcleral microvasculature using snapshot multispectral imaging. Exp Eye Res. 2016 Aug; 149:48-58.

53 Tate TH, Baggett B, Rice PF, Koevary JW, Orsinger GV, Nymeyer AC, et al. Multispectral fluorescence imaging of human ovarian and fallopian tube tissue for early-stage cancer detection. J Biomed Opt. 2016 May;21(5):56005.

54 Han Z, Zhang A, Wang X, Sun Z, Wang MD, Xie $T$. In vivo use of hyperspectral imaging to develop a noncontact endoscopic diagnosis support system for malignant colorectal tumors. J Biomed Opt. 2016 Jan;21(1):16001.

55 Kumashiro R, Konishi K, Chiba T, Akahoshi T, Nakamura S, Murata M, et al. Integrated endoscopic system based on optical imaging and hyperspectral data analysis for colorectal cancer detection. Anticancer Res. 2016 Aug;36(8): 3925-32.

56 Leavesley SJ, Walters M, Lopez C, Baker T, Favreau PF, Rich TC, et al. Hyperspectral imaging fluorescence excitation scanning for colon cancer detection. J Biomed Opt. 2016 Oct;21(10): 104003.

57 Panasyuk SV, Yang S, Faller DV, Ngo D, Lew RA, Freeman JE, et al. Medical hyperspectral imaging to facilitate residual tumor identification during surgery. Cancer Biol Ther. 2007 Mar;6(3):439-46

58 Kerbel RS. Tumor angiogenesis. N Engl J Med. 2008 May;358(19):2039-49.

59 Kerbel RS. Tumor angiogenesis: past, present and the near future. Carcinogenesis. 2000 Mar; 21(3):505-15.

60 Folkman J, Watson K, Ingber D, Hanahan D. Induction of angiogenesis during the transition from hyperplasia to neoplasia. Nature. 1989 May;339(6219):58-61.

61 Auvinen MI, Sihvo EI, Ruohtula T, Salminen JT, Koivistoinen A, Siivola P, et al. Incipient angiogenesis in Barrett's epithelium and lymphangiogenesis in Barrett's adenocarcinoma. J Clin Oncol. 2002 Jul;20(13):2971-9.

62 Kleespies A, Guba M, Jauch KW, Bruns CJ. Vascular endothelial growth factor in esophageal cancer. J Surg Oncol. 2004 Aug;87(2):95104

63 Tjalma JJ, Garcia-Allende PB, Hartmans E, Terwisscha van Scheltinga AG, Boersmavan Ek W, Glatz J, Molecular-Guided Endoscopy Targeting Vascular Endothelial Growth Factor A for Improved Colorectal Polyp Detection. J Nucl Med. 2015 Dec: jnumed.115.166975.
64 Griffiths EA, Pritchard SA, McGrath SM, Valentine HR, Price PM, Welch IM, et al. Increasing expression of hypoxia-inducible proteins in the Barrett's metaplasia-dysplasia-adenocarcinoma sequence. Br J Cancer. 2007 May;96(9): 1377-83.

65 Möbius C, Stein HJ, Becker I, Feith M, Theisen $\mathrm{J}$, Gais $\mathrm{P}$, et al. The 'angiogenic switch' in the progression from Barrett's metaplasia to esophageal adenocarcinoma. Eur J Surg Oncol. 2003 Dec;29(10):890-4.

66 Tjalma JJJ, Koller M, Linssen MD, Hartmans E, de Jongh S, Jorritsma-Smit A, et al. Quantitative fluorescence endoscopy: an innovative endoscopy approach to evaluate neoadjuvant treatment response in locally advanced rectal cancer. Gut. 2020 Mar;69(3):406-410.

67 Habr-Gama A, Perez RO, Proscurshim I, Campos FG, Nadalin W, Kiss D, et al. Patterns of failure and survival for nonoperative treatment of stage $\mathrm{c} 0$ distal rectal cancer following neoadjuvant chemoradiation therapy. J Gastrointest Surg. 2006 Dec;10(10):1319-28.

68 Smith JD, Ruby JA, Goodman KA, Saltz LB, Guillem JG, Weiser MR, et al. Nonoperative management of rectal cancer with complete clinical response after neoadjuvant therapy. Ann Surg. 2012 Dec;256(6):965-72.

69 Appelt AL, Pløen J, Harling H, Jensen FS, Jensen LH, Jørgensen JC, et al. High-dose chemoradiotherapy and watchful waiting for distal rectal cancer: a prospective observational study. Lancet Oncol. 2015 Aug;16(8):919-27.

70 Maas M, Beets-Tan RG, Lambregts DM, Lammering G, Nelemans PJ, Engelen SM, et al. Wait-and-see policy for clinical complete responders after chemoradiation for rectal cancer. J Clin Oncol. 2011 Dec;29(35):4633-40.

71 Renehan AG, Malcomson L, Emsley R, Gollins S, Maw A, Myint AS, et al. Watch-and-wait approach versus surgical resection after chemoradiotherapy for patients with rectal cancer (the OnCoRe project): a propensity-score matched cohort analysis. Lancet Oncol. 2016 Feb;17(2): 174-83.

72 Tjalma JJJ, Koller M, Linssen MD, Hartmans E, de Jongh S, Jorritsma-Smit A, et al. Quantitative fluorescence endoscopy: an innovative endoscopy approach to evaluate neoadjuvant treatment response in locally advanced rectal cancer. Gut. 2020 Mar;69(3):406-410.

73 Rath T, Bojarski C, Neurath MF, Atreya R. Molecular imaging of mucosal $\alpha 4 \beta 7$ integrin expression with the fluorescent anti-adhesion antibody vedolizumab in Crohn's disease. Gastrointest Endosc. 2017 Aug;86(2):406-8.

74 Atreya R, Neurath MF. Predicting therapeutic response by in vivo molecular imaging in inflammatory bowel diseases. Dig Dis. 2016; 34(5):552-7.

75 Atreya R, Neumann H, Neufert C, Waldner MJ, Billmeier U, Zopf Y, et al. In vivo imaging using fluorescent antibodies to tumor necrosis factor predicts therapeutic response in Crohn's disease. Nat Med. 2014 Mar;20(3):313-8.

76 Thong PS, Olivo M, Chin WW, Bhuvaneswari R, Mancer K, Soo KC. Clinical application of fluorescence endoscopic imaging using hypericin for the diagnosis of human oral cavity lesions. Br J Cancer. 2009 Nov;101(9):1580-4. 